\title{
ARTICLE
}

\section{Rawls's Point of View: A Systematic Reading of Justice as Fairness $^{*}$}

\author{
Marcos Fanton ${ }^{1}$ \\ https://orcid.org/0000-0001-5360-3647 \\ ${ }^{1}$ Universidade Federal de Santa Maria, Santa Maria/RS, Brazil
}

This paper offers a systematic reading of justice as fairness. By 'systematic reading' I mean an interpretation capable of presenting the rawlsian political conception as a coherent theoretical framework with all its stages of justification. I argue that the concept of point of view allows for this kind of interpretation. In the first part of this paper, I briefly discuss the difficulties of obtaining a comprehensive understanding of justice as fairness from some proposals previously set forth in the literature. In the second part, I make a formal definition of the concept of point of view and expound the main points of view in justice as fairness. Finally, I set out in detail what I will call here 'Rawls's point of view', the starting point of justice as fairness.

Keywords: John Rawls; justice as fairness; point of view; political contractualism; reflective equilibrium.

http://doi.org/10.1590/1981-3821202000020003

Correspondence: marcos.fanton@ufsm.br

This publication is registered under a CC-BY Licence.

\footnotetext{
*This article results from a Research Project funded by the National Council for Scientific and Technological Development (CNPq) - Process 439073/2018-9.
} 
n A Theory of Justice, the philosopher John Rawls aimed to "construct a

workable and systematic moral conception" that was sufficiently robust to rival utilitarian theories (RAWLS, 1999a, p. XVII). Utilitarianism has established itself as a popular and dominant moral theory due, in Rawls's view (1999a), to its progressive theoretical expansion and clarity thanks to constant collaborative revisions. This collective approach resulted in the creation of a comprehensive theory that can address issues ranging from moral dilemmas such as abortion, euthanasia and animal ethics, to global political problems, such as guarantees of rights and liberties, reforms in the penal system and the distribution of public goods and services. In this sense, justice as fairness represents a monumental effort to establish an alternative moral conception based on the contractualist tradition ${ }^{1}$. To this end, Rawls (1999a) intended to maintain the virtues of utilitarianism, such as clarity and systematicity, and to establish a productive criterion for solving questions of justice in order to avoid a purely intuitionist alternative.

Although this goal is an uncontroversial point in the literature, the problem of what we might understand as Rawls's systematic (1999a) conception of justice is not the object of such a consensus. It is nonetheless a fact that a significant part of the readers of justice as fairness have devoted some attention to understanding how this conception could be organized into a unified and coherent theoretical framework. How can we justify, for example, the use of a moral decision-making procedure as abstract as the original position in relation to our most basic intuitions about justice? How can we unite distinct procedural elements such as contractualist theory, the method of reflective equilibrium and political constructivism $^{2}$ ? How can we correctly understand the passage from the first argument of the original position, which deals with the choice of the principles of justice, to the second argument, which confirms the stability of a political

\footnotetext{
1It is known that Rawls have restricted his theory to principles concerning social institutions (the basic structure of society). To address various moral dilemmas, justice as fairness would need to establish (or at least allow for the establishment of) principles for moral agents. This was done, as is known, in 'A Theory of Justice', which provides a programmatic theoretical framework for discussing normative concepts concerning individuals, such as obligations, natural rights and permissions. For this, see RAWLS (1999a, §18).

${ }^{2}$ Hare (1973), Dworkin (1989), Cohen (1989), Qong (2007), and Larmore (2008).
} 
conception and introduces a theory of moral psychology ${ }^{3}$ ? After all, Rawls (1999a) himself had to deal with some of the unexpected consequences of his political conception and continually revised it throughout his career ${ }^{4}$.

It does not seem possible to obtain, to use John Chapman's famous expression (1975), a panoramic view of the Rawlsian 'Gothic Cathedral'. If this is the case, one of the main functions of political philosophy, according to Rawls (1999a) himself, cannot be satisfactorily fulfilled: namely to guide citizens' self-understanding about their political role within society and about the main ideas present in the public debate, such as equality, freedom, political authority, legitimacy and tolerance. For this, a political conception must meet two requirements: it must specify principles of justice that identify reasonable and rational ends for citizens and show that these ends can be expressed as a normative framework for a just society. Orientation in the 'conceptual space of ends' requires the articulation of a coherent and unified political conception resulting from the exercise of reason ${ }^{5}$.

My goal in this article is to advocate a systematic reading of justice as fairness. By 'systematic reading' I mean an interpretation capable of presenting Rawlsian political theory as a coherent and unified theoretical framework with all its stages of justification ${ }^{6}$. In this sense, I argue that the concept of point of view allows for this kind of interpretation.

This article is divided as follows. In the first part, I briefly discuss the difficulties of interpreting Rawls's theory systematically by reference to some of the proposals set out in the literature. In the second part, I make a formal definition of the concept of point of view and expound the existing points of view

\footnotetext{
3Wenar (1995), and Habermas (1995).

${ }^{4}$ Among the most important modifications, we can highlight Rawls' so-called 'political turn' in the 1980s, with the publication of 'Justice as Fairness: political, not metaphysical' (1985) and his 'Dewey Lectures on Kant' (1980). A list of the main modifications considered by Rawls is found in Weithman (2010, pp. 03-04).

${ }^{5}$ As far as I know, the detailed discussion of this function in Rawlsian political theory has not yet taken place. Rawls explicitly refers to Kant in a note at the beginning of Justice as Fairness: a Reformulation (RAWLS, 2001, p. 03). In addition, Rawls (2001) emphasizes, at various times, the importance of the search for coherence in our political judgments, as can be seen mainly in his discussion of reflective equilibrium (RAWLS, 2001, §10;1999a, § 07).

${ }^{6}$ This type of reading has already been undertaken by Weithman (2010), Baynes (1991), and Wenar (2004).
} 
in justice as fairness. This concept makes it possible to unify the stages of the theory and to draw together the contributions of various authors on the subject of partial views of justice as fairness. Finally, I set out in detail what I will call here 'Rawls's point of view', which marks the starting point of justice as fairness.

\section{Partial views of justice as fairness}

To address the problem of a systematic reading of justice as fairness, I will discuss two paradigmatic cases in the literature: 01. the relationship between the two arguments of the original position, the argument for the principles of justice and the problem of stability; and 02. the 'starting point problem', that is, the supposed foundations or basis for the Rawlsian political conception (2001, 1999a). The general idea here is to review previous efforts addressed at understanding justice as fairness as a coherent and unified theoretical framework. All the interpretations raised here say something true about justice as fairness. However, they fail to provide a systematic interpretation. In the end, as I observed above, I will argue that the concept of point of view is the most appropriate and economical option for doing so.

The first paradigmatic case deals with the relationship between the first argument of the original position, the choice for principles of justice, and the second argument, which discusses the stability of a reasonable political conception to achieve free and collective adherence on the part of citizens in a fair institutional arrangement. Until a few years ago, the discussion of both arguments was little explored. Most readers and critics focused on the argument for the two principles of justice and treated the second argument as superfluous or inconsistent ${ }^{7}$. Jürgen Habermas (1995), in his famous review of 'Political Liberalism', for example, argued that the Rawls's method of presenting the second argument is intractable. After choosing the principles of justice, Rawls should have left the acceptability test of his political conception to 'real citizens of flesh and blood'. Such discourses cannot be incorporated into political theory in the same way. Habermas claimed that this kind of approach was a very simplified and inaccurate anticipation of public deliberation (HABERMAS, 1995, pp. 120-121).

${ }^{7}$ A summary of this debate can be seen in Laden (2003). 
Benjamin Barber seems to have expressed a feeling common to some readers about this passage between arguments. For him, justice as fairness tried to reconcile incompatible elements: a certain 'Hobbesian contractarianism' of an individualistic and consequentialist nature, with Kantian psychological foundations based on duty and sociability. According to Barber (1989), there is some exaggeration in the justification; Rawls "seeks to burn his candle at both ends ... the brighter the better" (BARBER, 1989, p. 817). In other words, Rawls (1999a) modeled a kind of inconsistent moral agent. At the beginning of his theory, it owns some of the characteristics of a 'Hobbesian agent', which helps justify the choice of certain principles of justice that favor rational interests. Subsequently, in dealing with issues of mutual cooperation and obedience to political authority, Rawls (1999a) adds 'Kantian characteristics' to the agent in order to justify the priority given to obeying just norms instead of acting out of self-interest ${ }^{8}$.

Paul Weithman's book (2010), 'Why Political Liberalism?' presents an interpretation that seeks to clarify the unity of these different arguments. Weithman's goal is similar to the one proposed here: to develop and defend an interpretation that unifies different partial readings of justice as fairness ${ }^{9}$. His key reading is the idea of stability and its role in the so-called 'political turn' of the 1980s: "By asking what Rawls means by 'stability' and what threats to stability he wanted to avoid, we can unify the various perspectives on Rawls's work" (WEITHMAN, 2010, p. 05). Thus, Weithman's claim vis-à-vis justice as fairness is that it proposes a just and 'stable' political conception in a free and plural democratic society. The process of justifying the original position involves identifying collectively rational terms for social cooperation and demonstrating how, after the institutionalization and publicization of these terms, members of a just society would resolve tensions between the demands of justice with our views of justice (WEITHMAN, 2010, pp. 12-13). The two-step model of the original

\footnotetext{
${ }^{8}$ Leif Wenar discusses in detail the two parts of the original position argument and the possible contradictions between the stability argument with the principles of political liberalism (WENAR, 1995).

${ }^{9}$ For Weithman (2010), this goal is best accomplished if one asks for the reasons for Rawls' socalled 'political turn' and his view of political stability.
} 
position does not eliminate the public debate between real citizens, but only deepens and details the political ideals and values of justice as fairness ${ }^{10}$.

The second paradigmatic case involves what we might call the 'starting point problem' of justice as fairness, which was raised in the very first reviews of 'A Theory of Justice' and resonates even today'11. The objection here arises while questioning the relationship between our political intuitions (as Rawls, 1999a) would say, our considered judgments) and the original position. It seems that the latter presupposes arbitrary moral elements, such as a specific principle of treatment between persons or a specific moral motivation to adopt this specific device. As abstract as the original position is, say such critics, we find no moral justification for reflecting from it ${ }^{12}$.

According to Ronald Dworkin, one of the most famous representatives of this critique, the original position, to be sustained, needs to be understood as an 'intermediate conclusion' of a deeper moral theory that aims to spell out the psychological structure of our ability to make moral judgments about justice. The original position, in this sense, is a model of the mental process of moral agents, built on beliefs publicly shared by a particular community. Dworkin (1989) calls this method a 'constructive model' and defends it through a unified and ingenious interpretation of reflective equilibrium, contractualism and original position (DWORKIN, 1989, p. 26).

\footnotetext{
${ }^{10}$ At various times Rawls asserts the necessity for the second argument of the original position. We can list the following justifications for maintaining this step: 01 . better development of the idea of a well-ordered society and person (RAWLS, 2001, § 03-07); 02. distributive justice issues are not enough to choose political conceptions. Other values such as efficiency and stability need to be taken into account (RAWLS, 1999a, p. 07); 03. the exposition of moral psychology and, thus, the development of a sense of justice (RAWLS, 1999b, p. 429); 04. the assessment of the ability of citizens to reconcile the strains of commitment to justice and the demands of their own conception of the good (the 'unity of reason') (RAWLS, 1999a, p. 491); 05. the assessment of political stability upon 'special psychological tendencies', such as envy, self-interest and tendencies towards dominance or submission (RAWLS, 2001, §54). Political theory has this dual structure is due to the influence of Rousseau (RAWLS, 2007, p. 207).

${ }^{11}$ The problem was named by Carla Bagnoli (2014) in her article on moral and political constructivism. This kind of problem affects not only political constructivism but also reflective equilibrium and contractualism. For more on this, see Hare (1973), Dworkin (1989), Cohen (2008), Raz (1990), and Larmore (2008).

${ }^{12}$ Richard Hare (1973) and Ronald Dworkin (1989) may agree on one point in their criticisms of justice as fairness: as it is presented, the justification of the principles of justice is accomplished by an arbitrary normative procedure. Hare (1973) defines Rawls as a 'subjective intuitionist', while Dworkin (1989) seeks to remedy this problem by setting out the 'constructive method'.
} 
Very briefly, it can be said that the purpose of reflective equilibrium is, according to the constructive model, to select different publicly recognized moral intuitions to support principles of justice and make suggestions of models of social and political institutions (DWORKIN, 1989, p. 31). Thus, Dworkin suggests that Rawls's contractualism expresses such intuitions in a rightbased theory that protects fundamental interests, which the parties seek to secure through their veto power (DWORKIN, 1989, p. 46). That is, the original position presupposes a condition for the establishment of rights that protect the interests of individuals that must be taken into consideration by all. For Dworkin, Rawls's deep moral theory presupposes a "right to equal concern and respect in the design and administration of the political institutions that govern them" (DWORKIN, 1989, p. 50). Thus, we have the development of justice as fairness based on a specific moral element, which will regulate the choice of alternatives on distribution of rights and opportunities and on the regulation of the social, economic and political institutions of a given society.

This line of reasoning brought two strands of interpretation that have been developed in the contemporary literature. The first strand emphasizes the moral aspects (principles or ideals) that must be presupposed to admit the original position. That is, it is necessary to clarify the moral criterion that motivates the adoption of the original position. For Charles Larmore (2008), the original position only makes sense because it presupposes a moral commitment to reasonableness. We have taken the original position because we are already committed to being reasonable to each other and accept that this principle belongs to an order of moral values that is independent of our will ${ }^{13}$.

The second strand emphasizes the 'sociological aspect' of Dworkin's (1989) interpretation in relativizing the model of the original position to the public political culture. That is, the original position is developed so that we may reflect on certain existing social practices and their agents. From this we can draw two

\footnotetext{
${ }^{13}$ Larmore (2008) explicitly opposes political constructivism. His position is that of a rational intuitionist. Gerald Cohen was also famous for his general criticism of political constructivism. However, in his case, the problem lies in the incompatibility between different kinds of questions of justice: questions of justice as such (consideration of pure justice) and questions of rules governing the regulation of political and social institutions (considerations of the application of principles of justice) (COHEN, 2008, Ch. 07).
} 
conclusions. Firstly, the disposition of deliberation is appropriate only for certain contexts and cannot be unconditionally generalized. Second, if the description of such practices requires moral elements, as social cooperation in democratic societies does, this does not mean that they are arbitrary, but that such elements are necessary for their proper understanding ${ }^{14}$. For example, the description of the social practice of social cooperation requires the use of concepts such as reciprocity, interests and moral rationality ${ }^{15}$.

Aaron James $(2013 ; 2005)$ took this thesis further by arguing recently that Rawls has always reflected from existing social practices. This interpretation drawn from the difference in the development of justice as fairness for domestic issues, as developed in 'A Theory of Political Justice and Liberalism', and for international issues, as set forth in 'The Law of the Peoples'. For James (2005), the fundamental difference we must note here is the kind of social practice that Rawls takes for granted. In his major works, Rawls $(2005,1999$ a) focuses on the social practices performed by persons in the midst of social, political and democratic societies. In this context, the main point of social cooperation between people is the production of primary social goods, necessary for the development of the fundamental interests of each. In an international context, Rawls (1999c) cannot apply the same kind of moral device, because the social practices differs the interaction between peoples (not persons) and the production of social goods such as peace, national autonomy and mutual recognition between societies (JAMES, 2005, p. 300).

Thus, for James, the starting point of justice as fairness does not assume moral principles, but rather makes a 'constructive interpretation' of certain social practices and those who participate in them. This interpretation is developed in four steps: 01. the identification of an existing social practice and its purpose or good; 02 . the identification of the participants in this practice; 03 . the design or modelling of a device of reflection (such as the

\footnotetext{
${ }^{14}$ This kind of justification is made by Hart and his distinction between the internal and external aspects of social rules (HART, 2012).

${ }^{15}$ Here James makes a counterpoint to Robert Nozick's libertarian theory which, unlike Rawls, presupposes arbitrary normative concepts such as natural rights and his theory of entitlement. For more on this, see James, 2005, p. 290.
} 
original position); 04 . the determination of principles as necessary conditions for the organization of this practice (JAMES, 2005, p. 282).

In the end, in both paradigmatic cases, we do not have a common structure or formal element that can explain the development of all stages of justice as fairness. With Weithman's interpretation (2010), for example, we achieve a clearer picture of the argument of the original position in its fullest extent. But even the notion of points of view, which is crucial to properly understand his reading of the stability problem, is not developed. Weithman merely states that points of view are made up of "desires, rules of reasoning, and information" and form the basis for making decisions, making judgments on relevant issues, and for establishing the ultimate purposes of life (WEITHMAN, 2010, p. 59). The early stage of justice as fairness also lacks the richness of detail with which the stability problem is reconstructed. Weithman (2010) merely asserts (appropriately) that the Dworkin (1989) or Larmore (2008) readings are misguided. Rawls sought to defend his conception, Weithman argues, on the basis of political ideas such as society as a scheme of social cooperation and free and equal citizens. Thus, he says “if we can speak of the 'foundation' or 'foundations' of justice as fairness at all, what is foundational to it are conceptions of the person and of society that are found in democratic culture and that are made specific enough to generate political principles" (WEITHMAN, 2010, p. 12).

Dworkin's interpretation (1989) and its offshoots, while sticking to a detailed reconstruction of the 'foundational basis' of justice as fairness, give rise to two problems. In James' case $(2013,2005)$, we have no element common to all steps of the constructivist method, and worse, there is no separation between the two arguments from the original position. Larmore (2008) has the problem of making the argument from the original position a circular argument (a problem that Rawls himself was aware of). It is as if Rawls was presupposing a specific moral motivation (the principle of equal respect) for choosing principles of justice in the original position. In justice as fairness, this circularity is avoided by distinguishing between a thin theory and a thick theory of the good, that is, a theory based solely on the rational interests of the parties and a theory that later embodies the desire to be fair (the sense of justice informed by the principles of justice) (RAWLS, 2005, p. 492). There is therefore a need to distinguish different 
stages of development from Rawls's political conception to account for his explanation.

As I said at the beginning of this article, I believe both approaches say something true about justice as fairness and seem to be complementary. The concept of point of view is the most interesting formal element from which we can account for this integration and thereby to establish a systematic interpretation of justice as fairness. It is interesting not only due to its structure, as we shall see, but because Rawls himself divides his conception on this basis: "the point of view of the parties in the original position, the point of view of citizens in a well-ordered society, and the point of view of you and me who are setting up justice as fairness" (RAWLS, 2001, p. 45). These views are understood as stages of presentation and justification.

In the literature, Kenneth Baynes (1991) is the author who has given the most attention to this concept. In 'The Normative Grounds of Social Criticism' (1991), Baynes argues that the various criticisms against Rawls stem above all from a confusion between the description of the parties in the original position and the description of the citizens in a well-ordered society. His reading was guided by the indication of the three points of view above. However, Baynes' interpretation suffers from two serious limitations. In the first place, it takes the notion of 'point of view' as a given. Secondly, it merely clarifies the conceptions (ideas) of person and society throughout a strictly Kantian reading16.

My intention, therefore, is to rescue this reading and establish the concept of point of view as the organizing element of justice as fairness. However, in order to get real gains from this reading, we need to better define the complex structure of this concept and track its main modifications throughout the stages of presentation of justice as fairness. This will be done in the next section.

I will further argue that Rawls establishes four points of view on justice as fairness. In addition to the three points of view established by the Rawls himself, I believe that, from an analytical point of view, it is relevant to assume the point of view of the philosopher, which underwrites the procedures and elements that form the 'basis' for the construction of the political conception. I will call this

\footnotetext{
${ }^{16}$ For more on this subject, see Bercuson (2014) and Lloyd (2014).
} 
starting point 'Rawls's point of view' and it should be considered, in general terms, as historical and intuitive. It is historical, because it starts out from an understanding of a particular social and political context and is intuitive because it selects and excludes political convictions without a definite procedure (later, I will return to and develop these two characteristics) ${ }^{17}$.

\section{A systematic view of justice as fairness}

In his Lectures on the History of Political Philosophy, Rawls sets out some maxims that guide him in interpreting the classical authors from the tradition. One of these maxims is: "To understand their works, then, we must identify those points of view and how they shape the way the writer's questions are interpreted and discussed" (RAWLS, 2007, p. 103). This quote refers to the remark made by the philosopher Collingwood (1982) that the history of political theory is made up of ever-changing problems and solutions. Rawls (2007) does not accept the statement as a whole and limits its applicability to the contextualization of the different solutions of political problems that persists in almost every age, such as the nature of the political regime, the foundations and limits of political obligation, and/or the basis for individual rights. As Sharon Lloyd recently termed it, this "contextually situated and charitable interpretation" (LLOYD, 2014, p. 526) must always take into account the philosopher's point of view and presuppose his argumentative competence. Rawls demands that we look for the "answers that different authors have given to their (not our) questions" (RAWLS, 2007, p. 104).

With that in mind, we may be surprised at the content of Rawls's lessons (2007) and his attempt to scrutinize the tradition of political philosophers from their point of view. This is his way of distancing himself from the standardized interpretations of each contractualist. Hobbes (1996) and Locke (1988), for example, are read in the light of how they each interpreted the difficulties of their social context and what solutions they thought of these political stalemates. Hobbes (1996), says Rawls (2007), saw in the civil war between groups of rival religions the greatest threat in his time to peace and order. In other

\footnotetext{
${ }^{17} \mathrm{~A}$ historical reading of the original position is undertaken in Silva (2012) and, with a focus on economic theory, in Pontin (2013).
} 
words, its fundamental problem was the construction of a compelling philosophical argument about the establishment of an effective ruler powerful enough to stabilize the existing controversies. Locke (1988), on the other hand, aimed primarily at attacking Filmer's theory of divine right and offering political justification for resistance to the Crown through the doctrine of legitimate government among free, reasonable and rational persons. From this difference, Rawls concludes "that what may seem the same idea (the idea of the social contract) can have a very different meaning and use, given its role within a political conception as a whole" (RAWLS, 2007, p. 107).

The idea of point of view indicates the importance Rawls attaches to taking into account the philosophical problems and the social and political circumstances in which each philosopher lives (RAWLS, 2005, p. xiv). This definition roughly follows the strategy established at the beginning of the second part of A Theory of Justice ${ }^{18}$.

In section 31, Rawls develops a hypothetical four-stage application of the principles of justice in the basic structure of a democratic society. Principles, once chosen in the original position, become an 'Archimedean point' for the judgment of institutions. The parties gradually change their point of view according to the different issues of political justice: "Each stage is to represent an appropriate point of view from which certain kinds of questions are considered" (RAWLS, 1999a, p. 172). Thus, if the choice of principles requires the veil of ignorance to eliminate morally irrelevant information and/or motivations, the formulation and selection of infra-constitutional legislation and public policies require knowledge of facts of society itself, such as their natural, economic, social and cultural aspects (RAWLS, 1999a, p. 172).

In a later paragraph in the same work (s. 61), Rawls (1999a) analyzes the expression 'the good' in the sense of rationality and formalizes the above considerations. Something is good, in a first formulation, if and only if, it has the

\footnotetext{
${ }^{18}$ As is well known, Rawls' lectures on moral philosophy and political philosophy at Harvard have been compiled into two works (RAWLS, 2007; 2000) and have no direct relation to his systematic theoretical works, in which he expounds his own theory. However, the lectures here serve only as a limited reference: to further clarify the thinking behind his systematic works. Even without them, the interpretation remains intact. I would like to thank the reviewers for emphasizing this point.
} 
properties that are rational for someone to want things of its kind. However, this is not enough, Rawls observes, because the definition of such standards presupposes a similarity in the interests, capacities and circumstances of persons who desire such an object. In this sense, it is necessary to add such factors to the point of view of each particular person, and thereby relate them to criteria by which an object can be judged as excellent:

There always stands in the background a point of view from which an artifact, functional part, or role is being appraised, although of course this point of view need not be made explicit. This perspective is characterized by identifying the persons whose concerns are relevant for making the judgment, and then by describing the interests which they take in the object (RAWLS, 1999a, pp. 353-354).

Thus, we can only discuss the excellence of an object, such as a bicycle, if we have information about the 'relevant interests' of the person who will use that particular object in certain circumstances. In this case, it can be the type and distance of a trip, the personal reasons for it (leisure or competition), the financial budget and/or the aesthetic and/or technological considerations relating to the bicycle. There is no such thing as an absolutely good bike; the evaluation of its excellence will always depend on the cyclist's point of view.

Based on this explanation, I argue that Rawls (1999a) will assume this same conceptual framework when discussing political issues. One point of view forms the basis for making a moral decision or making a political judgment. Justice as fairness, in this sense, intends to establish a suitable moral point of view for the evaluation of social, political and economic institutions of modern democratic societies.

Basically, Rawls here denies the possibility of an answer to the classic question 'What is justice?' as formulated. To repeat myself: there can be no philosophical answer, as such, because there is no absolutely good principle of justice; the evaluation of the excellence of justice will always depend on the point of view of the moral agents and the circumstances of a given society ${ }^{19}$. Therefore, in Rawls's view, there are many possible contractual theories. Depending on how we model its main elements (rationality, information and interests of the parties,

\footnotetext{
${ }^{19}$ Let it be well understood that this 'point of view' 'is not subjective', as it is when we use it in everyday language to say, "This is my point of view ...".
} 
object and circumstances of the agreement, moral or political problems), we will have different theories (RAWLS, 1999a, p. 147)20. What differentiates Hobbes (1996), Locke (1988), Rousseau (1997), Kant (1991) and Rawls (1999a) is not just their political goals or principles, but the way each one modeled the contractualist elements 21 .

With this in mind, I wish to propose a formal definition of the concept of point of view ${ }^{22}$. Every point of view used in justice as fairness has a structure consisting of four elements: 01 . The specification of a particular social practice and the problems that require an evaluative judgment; 02. A description of the relevant (social and political) circumstances of the social practice and what information is accessible to those involved in such practice; 03. The identification of the persons (and/or constructs) involved and the description of their interests and their relevant intellectual and moral capacities; and 04. The description of the mode of reflection and/or deliberation suitable for people to be able make the evaluative judgment.

Each point of view should therefore play a suitable role or provide an appropriate normative perspective for judging the problems or conflicts presented in certain specific social circumstances that affect the persons involved.

The main assumption of the interpretation proposed here is the complexity of the structure of justice as fairness, which possesses, at least, four different points of view, each complementary to the others, and which accumulate, at each developmental stage, the results obtained at the previous ones. To try to make it even clearer and easier to understand, I have created a table with the main points of view developed in justice as fairness, summarized briefly into their most relevant elements.

\footnotetext{
${ }^{20}$ The formal structure of the initial situation of contractual theory is elaborated in Rawls, $2007, \S 17$.

${ }^{21}$ This problem is characteristic of contractualism and is current today. We can see this in Brian Skyrms (2004), who discusses the best formal models to exemplify the social contract problem. For Skyrms (2004), the best formal model is neither the original position nor the prisoner's dilemma, but the stag hunt game. We also find parallels with the discussion about the pluralism of models in economy, recently conducted by Rodrik (2015).

${ }^{22}$ Formalizations of the concept of point of view or, more specifically, of perspective, in contemporary political theory can be found in Gaus (2016) and Muldoon (2016).
} 
Table 01. The points of view of justice as fairness

\begin{tabular}{|c|c|c|c|c|}
\hline $\begin{array}{l}\text { Element/ } \\
\text { Point of view }\end{array}$ & Problems & $\begin{array}{l}\text { Circumstances of } \\
\text { justice }\end{array}$ & $\begin{array}{l}\text { Identification of } \\
\text { people and their } \\
\text { interests }\end{array}$ & $\begin{array}{l}\text { Mode of } \\
\text { reflection }\end{array}$ \\
\hline Rawls's & $\begin{array}{l}\text { Political conflicts in } \\
\text { a democratic } \\
\text { society and the } \\
\text { selection of } \\
\text { considered } \\
\text { judgments (fixed } \\
\text { points) and } \\
\text { political values }\end{array}$ & $\begin{array}{l}\text { Actual and } \\
\text { nonideal } \\
\text { conditions of } \\
\text { liberal democratic } \\
\text { societies }\end{array}$ & $\begin{array}{l}\text { Citizens } \\
\text { interested in } \\
\text { formulating a } \\
\text { conception of } \\
\text { justice }\end{array}$ & Abstraction \\
\hline Parties & $\begin{array}{l}\text { Fair scheme of } \\
\text { social cooperation } \\
\text { and distributive } \\
\text { justice }\end{array}$ & $\begin{array}{l}\text { General and } \\
\text { noncontroversial } \\
\text { facts of political } \\
\text { sociology, } \\
\text { economics, and } \\
\text { psychology. } \\
\text { Veil of ignorance } \\
\text { and symmetry of } \\
\text { the parties }\end{array}$ & $\begin{array}{l}\text { Free, equal and } \\
\text { rational persons } \\
\text { with higher- } \\
\text { order interests }\end{array}$ & $\begin{array}{l}\text { Rational } \\
\text { autonomy }\end{array}$ \\
\hline Citizens & $\begin{array}{l}\text { Mutual tolerance } \\
\text { and stability of a } \\
\text { political conception } \\
\text { of justice }\end{array}$ & $\begin{array}{l}\text { Conditions of a } \\
\text { well-ordered } \\
\text { society }\end{array}$ & $\begin{array}{l}\text { Citizens with full } \\
\text { developed moral } \\
\text { capacities }\end{array}$ & $\begin{array}{l}\text { Balance of } \\
\text { reasons } \\
\text { between } \\
\text { sense of } \\
\text { justice and } \\
\text { conception } \\
\text { of good }\end{array}$ \\
\hline Indexical & $\begin{array}{l}\text { Coherence between } \\
\text { normative } \\
\text { convictions and } \\
\text { political } \\
\text { conceptions of } \\
\text { justice }\end{array}$ & $\begin{array}{l}\text { Unrestricted } \\
\text { access to any kind } \\
\text { of information }\end{array}$ & $\begin{array}{l}\text { Citizens } \\
\text { interested in } \\
\text { grasping a } \\
\text { coherent and } \\
\text { unified } \\
\text { conception of } \\
\text { justice }\end{array}$ & $\begin{array}{l}\text { Reflective } \\
\text { equilibrium }\end{array}$ \\
\hline
\end{tabular}

Source: Elaborated by the author (2019).

The table is organized in the following way. In the columns we find each formal element of the concept of point of view. In the rows, we have the points of view of justice as fairness provided in a logical order of exposition and with their elements fulfilled. This is the explicit advantage of a systematic reading of Rawlsian theory: we can gain greater control over the methodological procedures and concepts involved in each step and verify changes in them without assuming statements or concepts from one step to another.

As I present it, justice as fairness should be read as follows. The first point of view, here called 'Rawls's point of view', undertakes the process of describing a particular social practice and modeling a deliberative procedure on that practice. It is at this stage that the elaboration of the fundamental ideas that characterize justice as fairness (the ideas, for example, of society, of the person and of the 
original position) and the choice of 'provisional fixed points' selected in the public political culture (in this case, the priority of right over ideas of the good or the inviolability of the person) (RAWLS, 2001, Part 01; 1999a).

Moreover, this view can be characterized as intuitive and historical. It is historical because it establishes Rawls's interpretation of the social and political circumstances of the society in which he lived and which problems should, in his opinion, be given priority. Thus, as we read his main theoretical works, we find the characterization of modern democratic societies and the persistent political problems that require philosophical reflection, such as the problems of justice, mutual tolerance and the relationship between the ideas of equality and liberty.

It is also intuitive, because there is no specific decision-making procedure for selecting these fundamental ideas or the political values of public political culture. How, for example, do we decide that justice should take precedence over the efficiency or stability of a political conception? Or, how do we decide that the original position is a better procedure than the Hobbesian state of nature?

This becomes clearer if we understand the role of intuition and the justification procedure in justice as fairness. First, we need to distinguish between the concept of considered judgments as moral and political intuitions and intuitionism as a political conception. The second is explicitly rejected by Rawls because it offers no criteria for judging the choice or priority of certain principles of justice. It is considered 'half of a conception' of justice because it denies the rational discussion of justice by stating that while we may understand a plurality of normative principles and values, we do not have "higher-order constructive criteria for determining the proper emphasis for the competing principles of justice" (RAWLS, 1999a, p. 30).

However, Rawls does not deny the important role that intuition plays in shaping political conceptions: "No doubt any conception of justice will have to rely on intuition to some degree" (RAWLS, 1999a, p. 36). Therefore, political theories should gradually restrict its reference to moral convictions or intuitions. This can be accomplished, for example, by developing decision-making procedures. Reference to such intuitions is not removed but restricted. The problem with intuitionism, in this sense, is not referring to our moral intuitions, but refusing to establish a criterion for moral decision-making. 
The second and third points of view cover the original position, the moral point of view of justice as fairness. Rivers of ink have already been dedicated to discussing this deliberation procedure, so I will stick to the essentials. First, it is important to note that the original position model contains two points of view the point of view of the parties and the point of view of the citizens in a well ordered society. Both views are hypothetical and are, therefore, part of the political conception of justice as fairness. Rawls (2005) gives us at least three justifications for the division of the argument: 01. each point of view deals with a distinct political issue; 02 . the division allows for a simplified choice for the principles of justice and thereby retains only fundamental interests as part of political deliberation (i.e. the parties are considered rationally autonomous); and 03. the second argument is relevant to better determine some political ideas, such as that of a well-ordered society and of the person ${ }^{23}$.

Secondly, the two points of view must follow an order of presentation: first, the parties choose the principles of justice and then, considering themselves to be citizens of a well-ordered society, ascertain whether such principles can remain stable over time. That is, the original position is a procedure with, basically, two situations of comparison between principles of justice: principles that guarantee primary social goods necessary for the development of our fundamental interests and principles that maintain a stable society with the support of its own citizens. The orderly division of arguments thus mirrors the moral intuition of the fundamental role of justice in democratic societies, as expressed in the opening sentence of 'A Theory of Justice': "Justice is the first virtue of social institutions" (RAWLS, 1999, p. 03). Other 'virtues', such as efficiency or stability, must be subordinate to it.

Thirdly, the original position model is the formalized expression of our political intuitions, and, in that sense, is the moment when we begin to constrain them. For example, our demands for a society based on reciprocal relations are formalized in fair conditions of agreement. This is accomplished through the relationship of symmetry between the parties and the veto power of

\footnotetext{
${ }^{23} \mathrm{On}$ this last point, see my previous comment on the justifications for the second argument of the original position.
} 
the least advantaged members (RAWLS, 2001, p. 18). The idea that moral and religious doctrines should not determine the political domain is expressed through the way Rawls comes to a list of primary goods or by distinguishing between political identity and non-political identity of free and equal persons (RAWLS, 2005, p. 30-31).

That is, the results of Rawls's point of view are included and implemented in both views of the original position. Let us examine this. In the first argument, the point of view of the parties in the original position defines a complex structure that allows for the establishment of an evaluative judgment on principles of justice that will regulate a specific social practice, namely the social cooperation of free and equal persons for the purposes of production of primary social goods. Its main problem is characterized as a problem of distributive justice and requires a collectively rational decision, that is, one whose result guarantees minimum social conditions for the development of the fundamental interests of the parties. The parties deliberate rationally and autonomously based on higher-order interests $^{24}$ and their psychological tendencies are very restricted, the idea of mutual disinterest being sufficient. It is important to note that at this stage the parties do not deliberate on the basis of a sense of justice but assume that everyone has the capacity to develop a sense of justice and thereby cooperate reciprocally. It is part of the rationale of the contract to be aware of this general psychological fact.

This is why Rawls can state that "the feeling that this conception of justice is egoistic is an illusion fostered by looking only at but one of the elements of the original position" (RAWLS, 1999a, p. 129). Although the first argument involves such simplifications, the second does not. It becomes important to make the idea of society as a system of social cooperation, which is now considered a wellordered society, more complex in the first place. And secondly, to determine the idea of a citizen with a determined sense of justice (i.e. informed by the principles of justice). In other words, Rawls (1999a) wants to know if persons who grew up and lived under a society regulated by justice as fairness will acquire a sense of

\footnotetext{
${ }^{24}$ Higher-order interests are defined by Rawls (1999a) as formal interests in securing conditions that foster the proper and full development of their moral faculties. In this sense, the parties to the original position must adopt principles of justice that guarantee such conditions.
} 
justice strong enough to opt for a plan of life that establishes interests of justice as priorities over selfish interests.

The structure of the stability problem is formulated on the basis of the prisoner's and the mutual assurance dilemmas. The general question that arises is a matter of individual rationality with detrimental collective consequences, not a problem of collective decision. Will citizens in a just society opt for justice even when faced with special psychological temptations such as envy, self-interest or the desire for domination/submission? Will a well-ordered society have a sufficient number of citizens who will develop such a sense of justice to maintain justice as fairness stable, and furthermore, will this willingness to act fairly be the object of mutual cognizance? Rawls (1999a) seeks to show, in the end, that in circumstances where justice is demanded (paying taxes, obeying traffic laws, showing mutual respect to political opponents), and in the knowledge that others are fair, acting fairly takes priority over defective actions (i.e. it is individually rational to be fair).

Therefore, a response to the possible objection of incongruence should take into account the steps of presentation (and justification), where the different elements of each point of view are modified to answer different questions, even though the results of the previous steps are retained. For example, if in the first argument the parties presuppose a capacity for a sense of justice, then in the second it is assumed that the parties, now citizens of a well-ordered society, have a sense of justice determined by the principles chosen in the first part 25 .

Finally, the fourth point of view listed in the table is the application of the 'indexical point of view' defined as the "point of view of you and me" (RAWLS, 2001, p. 45). Given the democratic conception of philosophy, Rawls addresses this conception to any citizen who has an interest in reflecting on political issues in a rational manner. The focus here is on the search for coherence between our

\footnotetext{
${ }^{25}$ The passage between the first and second stages of argumentation of the original position is evident in the following passage from 'Justice as Fairness': "The parties are to ask whether people who grow up in a society well ordered by the two principles of justice - the principles adopted in the first part of the argument - acquire a sufficiency strong and effective sense of justice so that they normally comply with just arrangements and are not moved to act otherwise, say, by social envy and spite, or by a will to dominate or a tendency to submit. If they do acquire a sufficiently strong sense of justice and are not swayed to the contrary by those special attitudes, then the outcome of the first part of the argument is confirmed and the argument for the two principles is complete" (RAWLS, 2001, p. 181).
} 
considered judgments about justice. It is a fact of political culture that we have conflicting political intuitions, as we do not in all cases consider their indepth practical consequences or the influences of our own interests. The effort to achieve a harmonious organization between such intuitions is expressed through the method of reflective equilibrium. Rawls (2001) characterizes this method as a process of going back and forth between our intuitions and principles of justice. Only after this adjustment can we affirm that a certain political conception will guide us in the political debate and be considered justified ${ }^{26}$.

This point of view expresses an activity of mutual adjustment between intuitions and political conceptions and it is the only one that interacts with all others in an unordered way. This kind of relationship expresses the nonfoundational characteristic of justice as fairness, in which no specific kind of intuition or idea is the basis for public justification or has unambiguous status (RAWLS, 2001, p. 44).

It is characterized as indexical, as it is always undetermined; it basically depends on the relationship that 'we' have with political conceptions and the reflection we make on which political conception is most reasonable for 'our' society. In this sense, this point of view will always depend on the reader and the social and political circumstances in which s/he lives.

\section{Rawls's point of view}

Now I would like to briefly reconstruct Rawls's point of view, as this is the least systematically explored stage in the literature. My intention is to show the reader the advantages of incorporating one more point of view (or at least the explicit ramifications of the third point of view). Having a clear understanding of Rawls's main assumptions (and what our own assumptions are) is necessary for any agreement on the plausibility of justice as fairness.

\footnotetext{
${ }^{26}$ It is worth mentioning here two things. The first concerns the ambiguity with which Rawls treats the method of reflective equilibrium: is it a process of reflection or a state of mind that serves as a normative ideal? Moreover, Rawls is ambiguous about the kind of person who performs reflective equilibrium: are they ordinary citizens or are they philosophers? The discussion of these issues can be seen in Scanlon (2003) and Daniels (2015).
} 


\section{The specification of the problems of a given social practice}

At the very beginning of the first conference of 'Political Liberalism', Rawls (2005) clearly sets out the two fundamental problems that justice as fairness seeks to address. The first is the problem of social justice, understood as the political conflict of the 'last two centuries' of democratic thought. We have not yet found, says Rawls, a common ground of agreement on how we should organize society and ensure the defense of the ideals of equality and freedom for all its citizens. This disagreement is described through Benjamin Constant's classic conceptual distinction between the "liberties of the ancients" and the "liberties of the moderns" (RAWLS, 2005, p. 05). To arbitrate between these two traditions, Rawls offers an egalitarian version of his political liberalism, expressed in the two principles of justice as a political conception capable of harmonizing the two values.

The second problem expresses the difficulty of finding a common basis for reconciling different lifestyles and worldviews present in modern democratic societies. Political liberalism takes seriously the diversity of ideas of the good in that it accepts pluralism as an inevitable product of free institutions (RAWLS, 2005, p. 03). Thus, the problem of social justice needs to be supplemented by the problem of mutual tolerance.

Both problems, as Rawls puts it, have a profound connection with the liberal tradition, in that their political resolution demands a criterion of reciprocal justification for all citizens (RAWLS, 2005, p. XLVII). Indeed, this link can be seen as an attempt to develop and establish an egalitarian version of liberalism as a viable political conception for democratic societies.

It is also from this tradition that Rawls describes the kind of social practice involved in the origin of political problems. Liberal societies are organized as a fair system of cooperation between free and equal persons for the purpose of producing primary social goods, that is, goods necessary for the development of our moral capacities (RAWLS, 2005, Conference VIII). Such a system presupposes, for its existence and stability, the knowledge and compliance of the citizens with public and reciprocal rules. These rules are not only followed but are part of the plan of life of the individuals. The idea of social cooperation in liberal societies, therefore, and its different ramifications (such as 
engaging in public deliberation or complying with legal rules in conflict of selfinterested goals) are part of Rawls's interpretation of the social practice that will be regulated by justice as fairness. This idea of social cooperation not only constitutes the list of the five fundamental ideals of this political conception but is the "central organizing idea" for its development (RAWLS, 2001, p. 05).

In this sense, the exposition of justice as fairness is not merely intended to persuade its readers of the reasonableness of the principles of justice or of the original position as the model of moral deliberation. It can be seen, at the same time, as a description of a historical perspective of the social world in which we live and of assessing the priority of particular political problems. Rawls (2005) wants to make explicit our understanding of basic ideas of our public political culture, such as the ideas of society and person.

One of the major reasons why there is no immediate perception of the importance of this stage in justice as fairness is Rawls's lack of space to discuss moral disagreements that emerge here. Early on in 'A Theory of Justice', Rawls discusses the notions of society and person in utilitarianism and contrasts them with the corresponding ideas in justice as fairness. He goes as far as to argue that for utilitarians society is considered an "efficient administration of social resources" (RAWLS, 1999a, p. 29) and persons are taken as agents who seek to maximize the fulfillment of their wants (RAWLS, 1999a, p. 24). From these two fundamental ideas, Rawls will say that utilitarianism gives priority to the increase of aggregate welfare over individual rights and freedoms, and thus realizes his famous critique that "utilitarianism does not take seriously the distinction between persons" (RAWLS, 1999a, p. 24). At bottom, even though Rawls is making comparisons between justice as fairness and utilitarianism, he cannot do much more at this point, as he is referring to the initial intuitions of each political conception (RAWLS, 1999a, p. 47). The decision on which best conception can only be realized through reflective equilibrium, which requires the complete development of each conception.

\section{Description of the social and political circumstances}

Part of the literature has credited the publication of 'Political Liberalism' as a 'step back' against communitarian criticism of the abstract model of the 
original position. Rawls (1999a) needed to close the gap between everyday political reflection and the abstract perspective of the parts in the original position ${ }^{27}$.

However, as we saw in the discussion of the second paradigmatic case, the 'basis' of justice as fairness is developed from certain abstract ideas implicit in public political culture. In this sense, in addition to the fundamental ideas of justice as fairness, Rawls develop his own understanding of the social and political world in which we live. This is what he calls the 'circumstances of justice'. This concept is developed in distinct excerpts from Rawls's major works and seeks to define not only the "historical conditions under which modern democratic societies exist" (RAWLS, 1999a, s. 24), but also the conditions under which human cooperation, and thereby a just society, are viable 28 .

These conditions involve the following generic common sense facts, listed below: 01. the fact of reasonable pluralism; 02. the fact of oppression; 03. the fact that a stable democratic regime must be freely and voluntarily supported by the majority of the politically active citizens; 04 . the fact that over time democratic societies will develop a political culture with shared democratic ideas; 05. the fact that no citizen of a democratic society needs to wait for or require the approval of others vis-à-vis their conception of the world or their lifestyle (Rawls (2005) has called this 'the burdens of judgment'); 06. the fact of the moderate scarcity of resources; and 07 . the fact that there are conflicting claims about the best distribution of the social advantages of mutual cooperation in society ${ }^{29}$. Ultimately, the concept of the circumstances of justice articulates Rawls's social and political worldview and is explicit to the reader ${ }^{30}$.

\footnotetext{
${ }^{27}$ For the purposes of this paper, however, I set aside any discussion of Rawls' 'political turn' and the central issue of 'Political Liberalism'. Implicitly, I follow the proposal set forth by Weithman (2010) in 'Why political liberalism?'.

${ }^{28}$ The idea of the circumstances of justice is paramount for the discussion of the function of realistic utopia and the proposition of an ideal theory of justice. The current discussion in the literature is based on the idea of feasibility. For more on this, see Wiens $(2015,2012)$ and Valentini (2012). For more on the different moments in which Rawls defines and restates this concept, see RAWLS, 1999a, $§ 22 ; 2001, \S \S 24$ and 59 (in particular, 59.1) and 2005, Intro.

${ }^{29}$ Other facts are also allowed, such as those that fall under the term "general facts about human society" (RAWLS, 1999a, p. 119).

${ }^{30} \mathrm{~A}$ view of the social and political world and this view can create conflicts and problems of political consensus is one of the main topics discussed by Gaus (2016).
} 


\section{Identification of the persons involved and their interests}

Rawls advocates a democratic conception of political philosophy. This means, among other things, that philosophy is part of the cultural background of contemporary democratic societies. Philosophers enter the political debate as equal citizens, who offer reflections that may be part of the collective knowledge of persons. While asserting a symmetrical political relationship between author and reader, Rawls assumes that philosophers possess not only the same moral authority but also the same moral and intellectual capacities of any other citizen. Philosophy demands only the exercise of reason and "has no special access to fundamental truths, or reasonable ideas, about justice and the common good, or to other basic notions" (RAWLS, 2007, p. 01). Thus, from the philosopher's point of view, the persons involved are all the politically engaged moral persons in a society.

However, upon entering the public debate, philosophers do so from a "philosophically motivated inquiry" (RAWLS, 1999b, p. 288). Its main interest is not to defend a specific political conception, but to investigate and systematize viable political conceptions for the political debate. As Rawls puts it, in defining the 'point of view of you and me', we assume that we are using justice as fairness to organize considered judgments at all levels of generality into a coherent view (RAWLS, 2001, p. 10).

In an even more precise sense, philosophical interests thrive upon practical interests, which are described by Rawls through the functions of political philosophy. We enter philosophy to solve problems of political conflict by developing a normative framework for guidance (RAWLS, 2001). This will be even clearer in the next section.

\section{Description of the appropriate mode of reflection and/or deliberation of persons.}

To understand the philosopher's mode of deliberation, I would like to quote a historical reference made by Rawls in 'Political Liberalism': 
We turn to political philosophy when our shared political understandings, as Walzer might say, break down, and equally when we are torn within ourselves. We recognize this if we imagine Alexander Stephens rejecting Lincoln's appeal to the abstractions of natural right and replying to him by saying: the North must respect the South's shared political understandings on the slavery question. Surely the reply to this will lead into political philosophy (RAWLS, 2005, pp. 44-45).

Using this episode, Rawls (2005) shows that Lincoln sought a political foundation for equality of persons that could be recognized and endorsed by the parties involved through the articulation of the abstract idea of natural law. That is, slavery was not attacked in public debate either from a particular moral conception or from an alternative view of human nature (something Stephens certainly did on the basis of the idea of racial supremacy). Instead, Lincoln argued that the institution of slavery violated the political principle of equality, as stated in the Declaration of Independence.

This philosophical engagement on public issues aiming for consensus has as its starting point a kind of "role modification" (RAWLS, 1999b, p. 290). In his article 'The Independence of Moral Theory', Rawls emphasizes the need to "put aside the urgency we feel to discover the true method of determining what we ought to do" and insist on observing different methods and moral positions that exist from a "neutral position and as impartially as possible" (RAWLS, 1999b, p. 290). In the face of a plethora of moral conceptions that do not find a common ground, philosophically motivated studies must "investigate the substantive moral conceptions that people hold, or should hold, under suitable defined conditions" (RAWLS, 1999b, p. 290).

Rawls gives this kind of reflection various labels: abstraction, modeling or idealization. This reflective process makes a selection of political ideals, values, or beliefs expressed at the most diverse levels of generality, implicit in public political culture, which offer the promise of constituting the elements of a political conception of justice. The fundamental ideas of justice as fairness, for example, described at the beginning of Rawls's works $(2005,2001)$, are elaborated precisely in this way.

For example, the original position is explained as the model of what we consider 'here and now' (that is, in democratic societies situated in the historical and social circumstances set out above) the fair conditions and reasonable 
restrictions of agreement between free and equal citizens (RAWLS, 2001, p. 24). The usual contexts of our daily lives make it difficult to arrive at an agreement as they are permeated by contingencies that affect our choices. In this sense, there is a need to establish a sufficiently abstract condition to guarantee agreement between the parties on a moral point of view.

The idea of the philosopher as an 'observer' of normative conceptions can be found in Rawls's philosophical work since the 1940s. David Reidy highlights this by drawing an evolutionary line from his youth writings on theology and ethics to his great works of political philosophy. Shortly after World War II, Rawls was concerned with the elaboration of a 'science of ethics' (REIDY, 2014, pp. 1213). The purpose of his project was to represent our capacity for practical reasoning by establishing models or 'deliberative machines' to distinguish appropriate and inappropriate moral judgments. When fueled by different moral judgments (inputs), the machine would output moral principles capable of explaining the moral judgments involved in a particular controversy. In the 1950s, this task of explaining our 'moral sensibility' was complemented by the task of justification, developed by comparison with rival moral conceptions of our ability to reflect about free and rational persons. Such tasks were part of what Rawls called "moral philosophy" (REIDY, 2014, pp. 18-19).

Regarding the process of abstraction, I would like to make a final comment. We know that Rawls restricted, but did not remove the role of intuitions from his political conceptions. Thus, we may ask ourselves: is there any decisionmaking procedure for the characterization and choice of considered judgments or for the political ideas and values fundamental to Rawlsian theory? Or is there any procedure for prioritizing one idea over another, such as the inviolability of people or the idea of society as an equitable system of cooperation? How abstract should the initial set of ideas of a political theory be?

In 'The Independence of Moral Philosophy', Rawls states, in a rather intuitionistic tone, that we must develop those conceptions that "strike us as most promising" for political consensus (1999b, p. 289). In 'Political Liberalism', this tone is maintained when Rawls mentions the "fact that we feel coerced", "impelled" or even "surprised" by the development and deepening of certain judgments weighed on principles and criteria for a political conception (RAWLS, 2005, p. 54). 
Therefore the intuitive selection or exclusion of such 'first' elements is only justified after understanding the general framework of the political conception and serving its political objectives.

\section{Conclusion}

My main intention in this article was to offer a systematic reading of justice as fairness. The immediate gains derived from this can be seen in the kind of understanding we now have of the Rawlsian theory of justice. This interpretation is first and foremost complete, as it covers all stages of the argumentation of justice as fairness. Secondly, it is structurally comprehensive because, in addition to allowing for the differentiation of stages, it allows for the definition and distinction of the main elements of each stage and thereby maintaining a certain conceptual and methodological control. Finally, and thirdly, it seeks to make clear the coherence of the theory by showing that the relationship between its components is free of gaps and contradictions.

As argued in the first part of the text, there is a continuing concern in the literature to account for this kind of interpretation. From Ronald Dworkin (1989) to Paul Weithman (2010) and Aaron James (2013), we find different versions to accommodate justice as fairness as a coherent and unified whole. However, in all versions there is always some step missing, or else the interpretation does not provide an element capable of integrating all the stages and guiding readers through the established modifications. An interpretation based on the notion of point of view fills this gap.

A second gain from the reading proposed here comes from the analytical distinction of Rawls's point of view. Through this resource, we gain greater clarity on how Rawls understood his social and political world and what the main political problems and values were that came to his attention and received priority. However, it is up to us here and now to ask the same questions Rawls himself posed to the contractualistic tradition: Are these circumstances depictured by these thinkers the same political circumstances that we actually live in nowadays? Are these problems the same political problems and values that we should give priority to nowadays? Is there a consensus in our public political culture on any specific political values or a specific understanding of our 
political and social world? ${ }^{31}$ If we can agree, for example, that issues of distributive justice and mutual tolerance are central to our society and that our society should be viewed as a scheme of social cooperation between free and equal persons, then, it seems that this agreement is the first step while agreeing with later theoretical developments of justice as fairness.

Finally, one last gain can be seen in the capacity that this type of reading allows for the formation of a research program. As some readers familiar with Rawls's work may have noticed, certain elements or stages are absent from my interpretation. For example, the sequence of stages of application of the principles of justice following the choice in the original position was not set out in detail. The ideal of public reason or the principle of liberal legitimacy, which creates particular difficulties, is also absent given the current discussion of its exact location. If the idea of point of view and the orderly presentation of justice as fairness, as proposed, help us reflect on such concepts and can be further developed, then I will have achieved my goal. The purpose of this reading is also to serve as a basis for the integration of different studies on political liberalism and the improvement of diverse political conceptions.

As Rawls said (1999a), utilitarianism has only become a consistent and widespread moral theory due to its capacity for constant reformulation through integrated work between different thinkers. Likewise, I believe that by elaborating a systematic and complex framework, Rawls did not intend, in isolation, to create an alternative to utilitarianism, but rather to allow for a theoretical framework capable of establishing a theoretical point of convergence point that could be refined over time. It seems that this was his intention while denying the claim of originality of justice as fairness, since it should be understood as an update of political contractualism:

\footnotetext{
${ }^{31}$ There is a growing literature among liberal public reason theorists regarding the divergence between political perspectives. These authors argue that there is a deep divergence between conceptions of the social and political world that cannot be retranslated in terms of preference and priorities. In this sense, there is a concern to understand how social and legal norms can be justified for different political perspectives. Among the authors who discuss such problems, we can refer to D'Agostino (1996), Gaus (2016), Muldoon (2016), Vallier (2019), Chung and Kogelmann (2018).
} 
My ambitions for the book will be completely realized if it enables one to see more clearly the chief structural features of the alternative conception of justice that is implicit in the contract tradition and points the way to its further elaboration (RAWLS, 1999a, p. XVIII).

Translated by Fraser Robinson

Submitted on May 07, 2018

Accepted on October 28, 2019

\section{References}

BAYNES, Kenneth (1991), The normative grounds of social criticism. New York: State University of New York Press. 256 pp..

BAGNOLI, Carla (2014), Starting points: Kantian constructivism reassessed. Ratio Juris. Vol. 27, № 03, pp. 311-329.

BARBER, Benjamin (1989), Justifying justice: problems of psychology, politics and measurement in Rawls. In: Reading Rawls: critical studies on Rawls's 'A theory of justice'. Edited by DANIELS, Norman. Stanford: Stanford University Press. pp. 292-318.

BERCUSON, Jeffrey (2014), John Rawls and the history of political thought: the rousseauvian and hegelian heritage of justice as fairness. New York: Routledge. 150 pp..

COHEN, Gerald A. (2008), Rescuing justice and equality. Cambridge: Harvard University Press. 448 pp..

COHEN, Joshua (1989), Democratic equality. Ethics. Vol. 99, № 04, pp. 727-751.

COLLINGWOOD, Robin George (1982), An autobiography. New York: Oxford University Press. 192 pp..

CHAPMAN, John (1975), Rawls's theory of justice. The American Political Science Review. Vol. 69, № 02, pp. 588-593.

CHUNG, Hun and KOGELMANN, Brian (2018), Diversity and rights: a social choicetheoretic analysis of the possibility of public reason. Synthese. Vol. 197, pp. 839-865.

D’AGOSTINO, Fred (1996), Free public reason: making it us as we go. Oxford: Oxford University Press. 203 pp..

DANIELS, Norma (2015), Relective equilibrium. In: The Cambridge Rawls Lexicon. Edited by MANDLE, Jon and REIDY, David A.. Cambridge: Cambridge University Press. pp. 711-716. 
DWORKIN, Ronald (1989), The original position. In: Reading Rawls: critical studies on Rawls's 'A theory of justice'. Edited by DANIELS, Norman. Stanford: Stanford University Press. pp. 01-12.

GAUS, Gerald (2016), The tyranny of the ideal: justice in a diverse society. Princeton: Princeton University Press. 328 pp..

HABERMAS, Jürgen (1995), Reconciliation through the public use of reason: remarks on Jonh Rawls's political liberalism. Journal of philosophy. Vol. 92, № 03, pp. 109-131.

HARE, Richard M. (1973), Rawls's theory of justice. Philosophical Quarterly. Vol. 23, № 91, pp. 144-155.

HART, Herbert Lionel Adolphus (2012), The concept of law. Oxford: Oxford University Press. 380 pp..

HOBBES, Thomas (1996), Leviathan: revised student edition. Cambridge: Cambridge University Press. 618 pp..

JAMES, Aaron (2013), Political constructivism. In: A companion to Rawls. Edited by MANDLE, Jon and REIDY, David A.. Oxford: Wiley-Blackwell. pp. 251-264.

JAMES, Aaron (2005), Constructive justice for existing practice: Rawls and the status quo. Philosophy and public affairs. Vol. 33, № 03, pp. 281-316.

KANT, Immanuel (1991), Political writings. Cambridge: Cambridge University Press. 323 pp..

LADEN, Anthony (2003), The house that Jack built: thirty years of Reading Rawls. Ethics. Vol. 113, № 02, pp. 367-390.

LARMORE, Charles (2008), The autonomy of morality. Cambridge: Cambridge University Press. 288 pp..

LOCKE, John (1988), Two treatises of government. Cambridge: Cambridge University Press. 478 pp..

LLOYD, Sharon A. (2014), Learning from the history of political philosophy. In: $A$ companion to Rawls. Edited by MANDLE, Jon and REIDY, David A.. Oxford: Wiley-Blackwell. pp. 526-545.

MULDOON, Ryan (2016), Social contract theory for a diverse world: beyond tolerance. New York: Routledge. 142 pp..

PONTIN, Fabrício (2013), Political economy and the roots of Rawls' original position. Dois Pontos. Vol. 10, № 01, pp. 177-194. 
QONG, Jonathan (2007), Contractualism, reciprocity, and egalitarian justice. Politics, Philosophy \& Economics. Vol. 06, № 01, pp. 75-105.

RAZ, Joseph (1990), Facing diversity: the case of epistemic abstinence. Philosophy and Public Affairs. Vol. 19, № 01, pp. 03-46.

RAWLS, John (2007), Lectures on the history of political philosophy. Cambridge: Harvard University Press. 496 pp..

RAWLS, John (2005), Political liberalism. New York: Columbia University Press. $576 \mathrm{pp}$.

RAWLS, John (2001), Justice as fairness: a restatement. Cambridge: Harvard University Press. 240 pp.

RAWLS, John (2000), Lectures on the history of moral philosophy. Cambridge: Harvard University Press. 416 pp..

RAWLS, John (1999a), A theory of justice. Cambridge: Harvard University Press. $560 \mathrm{pp}$.

RAWLS, John (1999b), Collected papers. Cambridge: Harvard University Press. 672 pp..

RAWLS, John (1999c), The law of peoples. Cambridge: Harvard University Press. 208 pp..

RAWLS, John (1985), Justice as fairness: political, not metaphysical. Philosophy \& Public Affairs. Vol. 14, pp. 223-251.

RAWLS, John (1980), Kantian constructivism in moral theory: the Dewey lectures. Journal of Philosophy. Vol. 77, pp. 515-572.

REIDY, David (2014), From philosophical theology to democratic theory: early postcards from an intellectual journey. In: A companion to Rawls. Edited by MANDLE, Jon and REIDY, David A.. Oxford: Wiley-Blackwell. pp. 09-30.

RODRIK, Dani (2015), Economics rules: why economics works, when it fails, and how to tell the difference. Oxford University Press. 272 pp..

ROUSSEAU, Jean-Jacques (1997), The social contract and other later political writings. Cambridge: Cambridge University Press. 341 pp..

SCANLON, Thomas M. (2003). Rawls on justification. In: FREEMAN, S. (Ed.). The Cambridge Companion to Rawls. Cambridge University Press.

SILVA, Walter Valdevino Oliveira (2012), Democracia e individualismo: a igualdade como princípio organizador. Porto Alegre: Edipucrs. 107 pp.. 
SKYRMS, Brian (2004), The stag hunt and the evolution of social structure. Cambridge: Cambridge University Press. 149 pp..

VALENTINI, Laura (2012), Ideal vs. non-ideal theory: a conceptual map. Philosophy Compass. Vol. 07, № 09, pp. 654-664.

VALLIER, Kevin (2019), Must politics be war? Restoring our trust in the open society. Oxford: Oxford University Press. 256 pp..

WEITHMAN, Paul (2010), Why political liberalism? On Rawls's political turn. Oxford: Oxford University Press. 400 pp..

WENAR, Leif (2004), The unity of Rawls's work. Journal of moral philosophy. Vol. 01, № 03, pp. 265-275.

WENAR, Leif (1995), Political liberalism: an internal critique. Ethics. Vol. 106, № 01, pp. 32-62.

WIENS, David (2015), Political ideals and the feasibility frontier. Economics \& Philosophy. Vol. 31, № 03, pp. 447-477.

WIENS, David (2012), Demands of justice, feasible alternatives, and the need for causal analysis. Ethical Theory \& Moral Practice. Vol. 16, № 02, pp. 325-338. 